\title{
LAS PRIMERAS CANONJÍAS DE OFICIO EN LA CATEDRAL DE VALENCIA. UN EPISODIO DE LA RIVALIDAD ENTRE OBISPOS Y CABILDOS DURANTE EL SIGLO XVII*
}

\author{
POR \\ EMILIO CALLADO ESTELA \\ Universidad CEU - Cardenal Herrera
}

\begin{abstract}
RESUMEN
Durante el siglo XVII las catedrales de la Monarquía Hispánica constituyeron un campo de batalla. Mucho tuvo que ver en ello la recuperación de la autoridad de los obispos, iniciada con la Época Moderna frente a las tendencias descentralizadoras del Medievo y culminada en Trento. Contra ella se rebelaron los cabildos, con suficiente autonomía todavía para oponerse al báculo episcopal en defensa de sus derechos. El establecimiento de las canonjías de oficio fue uno de los más recordados episodios al respecto. En diócesis como Valencia provocó un recrudecimiento de las relaciones entre unos y otros que en 1671 -1673 retrotrajo la situación a los peores tiempos en la historia de la Iglesia local.
\end{abstract}

PALABRAS CLAVE: Iglesia; obispos; cabildos; Trento; Siglo XVII; Valencia.

\section{THE FIRST CANONRIES DE OFICIO AT VALENCIA CATHEDRAL. AN EPISODE OF RIVALRY BETWEEN BISHOPS AND CHAPTERS DURING THE $17^{\text {TH }}$ CENTURY}

\begin{abstract}
During the $17^{\text {th }}$ century, cathedrals in Hispanic Monarchy became a true battleground between bishops and canons. After the decentralizing trends in medieval period, the restoration of bishops' authority in the beginnings of the Early Modern Age was a crucial fact, culminating in the Council of Trent. But chapters, managing enough autonomy, rose up against the Episcopal authority in order to conserve their rights. The establishment of the so-called canonries de oficio was one of the most important episodes in that process. Fighting between bishops and canons intensified in dioceses like Valencia, where the situation in the period 16711673 evoked the worst past days in the history of local Church.
\end{abstract}

KEY WORDS: Church; bishops; chapters; Council of Trent; $17^{\text {th }}$ century; Valencia.

CómO CITAR ESTE ARTículo / CITATION: Callado Estela, E. 2019. «Las primeras canonjías de oficio en la catedral de Valencia. Un episodio de la rivalidad entre obispos y cabildos durante el siglo XVII». Hispania Sacra 71, 143: 179-189. https://doi.org/10.3989/hs.2019.013

\author{
Recibido/Received 17-07-2017 \\ Aceptado/Accepted 01-08-2017
}

Durante el siglo XVII las iglesias catedrales de la Monarquía Hispánica fueron un campo de batalla. ${ }^{2}$ Mucho debería este estado a la recuperación de la autoridad de los obispos, que iniciada con los albores de la Época Moderna, frente a las tendencias descentralizadoras del Medievo, había culminado

Este trabajo forma parte del proyecto de investigación $L a$ Catedral Barroca. Iglesia, sociedad y cultura en la Valencia del siglo XVII, financiado por el Ministerio de Economía y Competitividad del Gobierno de España (HAR2016-74907-R)

1 ecallado@uchceu.es/ORCIDiD:https://orcid.org/0000-0003-1845-1179

2 Marín López 2007: 80-83. También Díaz Rodríguez 2010. en Trento. ${ }^{3}$ Contra ella se rebelaron los cabildos, con suficiente autonomía todavía para oponerse al báculo episcopal en defensa de aquellos privilegios, libertades y exenciones jurisdiccionales que se resistían a perder, según dejó ya escrito A. Domínguez Ortiz. ${ }^{4}$ El establecimiento de las canonjías de oficio, llamadas también de oposición por la forma en que se proveían, constituiría uno de los más recordados episodios al respecto en diócesis como Valencia, con una larga tradi-

3 Véanse entre otros los estudios pioneros de Cereceda 1944; Marín Martínez 1948 o Goñi Gaztambide 1975. Más reciente, Fernández Terricabres 2000: 331-359.

4 Domínguez Ortiz 1985: 246. 
ción en enfrentamientos de semejante cariz. ${ }^{5}$ Aquí la tensión prelados-capítulos experimentó a cuenta de estas prebendas -en realidad solo de la lectoral - un recrudecimiento sin precedentes que entre 1671 y 1673 retrotrajo la situación a los peores tiempos en la historia de la Iglesia local, cuyas conexiones con la sociedad regnícola amenazaron con hacer saltar en pedazos el orden y la estabilidad de la capital levantina.

\section{CUATRO CANONJÍAS PARA CUATRO OFICIOS}

Canónigos, dignidades, pavordes y beneficiados integraban el clero de la catedral de Valencia, aunque solo los primeros constituían el cabildo metropolitano stricto sensu al que pertenecía el gobierno de la seo y del que - a diferencia de lo común en otras sedes eclesiásticas - estaban excluidos los demás caso de no poseer también una canonjía, algo cada vez más infrecuente. ${ }^{6}$ Veintitrés eran tales prebendados desde época bajomedieval, provistos directamente por Roma durante los meses de reserva apostólica, es decir enero, febrero, abril, mayo, julio, octubre y noviembre, y por la mitra el resto del año; doce de ellos presbiterales, seis diaconales y cinco subdiaconales desde 1566 a imagen y semejanza del colegio cardenalicio según disposición del papa Pío V. ${ }^{7}$

La asignación a estos canónigos de algunos oficios esenciales para el funcionamiento de la iglesia mayor valentina, al margen de los inherentes a la propia condición capitular y ya por oposición, se produjo con bastante posterioridad como en muchos otros lugares de la periferia peninsular. ${ }^{8}$ Quizá no el penitenciario, que dedicado a resolver dudas y casos de conciencia y confesar a los ministros del templo venía funcionando en la práctica como un canonicato más, cubierto al modo tradicional, desde $1557 .{ }^{9}$ Pero sí el magistral, al que atañía predicar la Palabra de Dios; el doctoral o asesor capitular en materia jurídica; y el lectoral, aún con orígenes en el IV Concilio de Letrán sancionado definitivamente por Trento para la interpretación y exposición de la Sagrada Escritura. ${ }^{10}$

Todavía en 1626 las cortes valencianas reclamaban su establecimiento para mayor lustre y prestigio del Reino, al estilo de las Iglesias de Castilla, previo examen entre quienes reunieran los requisitos contemplados en cada caso - preferiblemente de edad madura, graduados en Teología o Cánones y en universidades reconocidas - y sin intervención ninguna del pontífice:

5 Durante la primera mitad del Seiscientos como poco. Callado Estela 2000: 207-258, 2011.

6 Epitome sive compendium constitutionum sanctae metropolitanae Ecclesiae Valentinae. 1582: 8 y ss. Valencia: s. e.

7 Archivo de la Catedral de Valencia[=ACV]. Leg. 3605.

8 Cataluña por ejemplo, Jiménez Sureda 1992: 237-243. Además de las Iglesias hispánicas de Indias, Pérez Puente 2012: 63.

9 Pons Alós y Cárcel Ortí 2013: 103. Había sido Diego Bru el primer canónigo en hacer las veces de penitenciario, ya a finales de la década de los cincuenta del siglo XVI. ACV. 691, Llibre de possessions de l'arquebisbat, dignitats y canonicats de València, 1535-1740: s.f. Oficio asignado en 1571 por el arzobispo Ribera a la prebenda del doctor Francisco Tudela, aún sin ratificación apostólica ni modificación, pues, en su forma de provisión. Archivo de la Corona de Aragón [=ACA]. Consejo de Aragón. Leg. 803: 1/101. A este último le sucedería su sobrino Eugenio Tudela en 1598, Vicente Pérez a partir de 1623 y el doctor don Tomás Antonio Corbí desde 1639. Véase cuadro I.

10 El sacrosanto Concilio de Trento. Trad. de I. López de Ayala. ses. V, Decreto sobre la reforma. Cap. I Que se funden cátedras de Sagrada Escritura. 1845: 26-30. Barcelona: Imprenta de Ramón Martín
Les quals quatre canongies hajen de provehir-se en les persones més benemèrites e idònees, precehint examen y oposició pública faedora en lo capítol de la seu, llegint en punts de 24 hores y arguhint los opositors ad invicem y també los capitulars que voldran, ab la porta uberta que tots ho vejen. $Y$ fetes les oposicions les hajen de votar y voten lo arquebisbe de València o son vicari capitular y tots los canonges que se hauran trobat en les oposicions y exàmen y no altres [...]. Y lo que tindrà més vots reste provehit en la canongia [...]; y en cas de paritat de vots prevaleixca la part per qui votara lo arquebisbe [...] o son vicari capitular, de manera que en la provisió no tinga més de un vot lo prelat o son vicari y calitat en los casos de paritat. Y per d'açò se obtinga bul·la particular de la erecció y aplicació destes quatre canongies y que en elles no puixa entrar la alternativa per ningun cas, ni sa santedat per via de reserves ni en altre qualsevol modo per regles de Cancelleria vel alias introduhit, puixa entrometres en la provisió de dites canongies ni alguna de aquélles, sinó que resten tots temps y en qualsevol casos a provisió dels capítols en la forma sobredita. ${ }^{11}$

Efectivamente Felipe IV prometió su intercesión ante la Santa Sede para que las primeras vacaturas catedralicias se afectaran a tales empleos en los términos solicitados, perjudiciales para Roma por cuanto suponían renunciar a todo control directo sobre la provisión de estas prebendas. ${ }^{12}$ Así que ni Urbano VIII ni Inocencio X se avendrían a ello, retrasándose la asignación hasta el pontificado de Alejandro VII en $1657 .{ }^{13}$

Un par de vacantes sucesivas y la colaboración del ordinario diocesano facilitarían que, al año siguiente mismo, se anunciaran oposiciones para las canonjías doctoral y magistral. Haríase mediante edictos públicos, distribuidos dentro y fuera de la diócesis a nombre de la mitra y el propio cabildo, y sobre contenidos de Decretales la primera y Biblia la segunda, imponiéndose respectivamente en los ejercicios públicos José Avellá y Melchor Fuster. ${ }^{14}$

Penitenciario continuó siéndolo entretanto don Tomás Antonio Corbí, a cuya muerte en 1675 se convocaría el oportuno concurso para adecuar este oficio a la nueva disposición pontificia. ${ }^{15}$ La plaza fue a parar entonces al doctor Juan García. ${ }^{16}$

11 Furs, Felipe IV, 1626: CLXXX, 34.

12 A propósito del asunto véase el excelente estudio de Barrio Gozalo 2010. También Díaz Rodríguez 2012: 251 y ss.

13 Bulla sanctissimi domini nostri Alexandri, Divina Providentia papae VII, super provisione canonicatum doctoralis, magistralis et poenitentiarii Ecclesiae Valentinae, catholicae maiestatis Philippi Quarti, regis nostri piis votis impetrata. 1676. Valencia: s. e.

14 El primero el 30 de marzo tras la promoción episcopal a Tarragona del canónigo Francisco de Rojas; y el segundo el 12 de abril, a la muerte de Marcelo Sanou. ACV. 691, Llibre de possessions: 124v-125. Avellá, doctor en ambos Derechos, había regentado hasta entonces sendas pavordías de Cánones y Leyes (Felipo Orts y Callado Estela 2016: 209). Doctor y también pavorde, en este caso de Teología, Fuster fue una de las más destacadas figuras del cabildo metropolitano seiscentista (Ibid.: 222-223). Así lo confirma la infinidad de ministerios ocupados a lo largo de su vida, como juez comisario apostólico; oficial, vicario general, visitador y juez del arzobispado de Valencia; examinador sinodal de la diócesis valentina; síndico del estamento eclesiástico; y contador de la Diputación. O el vasto legado editorial que dejó tras su fallecimiento en 1686, con una docena larga de sermones impresos y algunas otras obras (Ximeno 1747-1749: II, 99-102)..

15 Desde 1655 había compaginado este desempeño con el cargo de canciller juez de competencias entre las jurisdicciones real y eclesiástica para el reino de Valencia (Canet Aparisi 1986: 234).

16 Posesionándose de ella el 24 de octubre del mismo 1675. ACV. 691, Llibre de possessions: 137v. 


\begin{tabular}{|c|c|c|c|c|}
\hline \multicolumn{5}{|c|}{$\begin{array}{c}\text { CUADRO } 1 \\
\text { Primeros titulares de las canonjías de oficio en la Catedral de Valencia }\end{array}$} \\
\hline \multirow{6}{*}{ PROVISIÓN DIRECTA } & PENITENCIARIA & DOCTORAL & MAGISTRAL & LECTORAL \\
\hline & $\begin{array}{c}\text { Diego Bru } \\
1558-[1581]\end{array}$ & \multirow{5}{*}{---} & \multirow{5}{*}{---} & \multirow{5}{*}{$\begin{array}{c}\text { Eusebio Falcó } \\
1673-1678\end{array}$} \\
\hline & $\begin{array}{l}\text { Francisco Tudela } \\
\text { 1581-1598 }\end{array}$ & & & \\
\hline & $\begin{array}{l}\text { Eugenio Tudela } \\
1598-1623\end{array}$ & & & \\
\hline & $\begin{array}{l}\text { Vicente Pérez } \\
1623-1639\end{array}$ & & & \\
\hline & $\begin{array}{l}\text { Tomás Antonio Corbí } \\
\text { 1639-1675 }\end{array}$ & & & \\
\hline \multirow[b]{2}{*}{ POR OPOSICIÓN } & $\begin{array}{l}\text { Juan García } \\
\text { 1675-[1685] }\end{array}$ & $\begin{array}{l}\text { José Avellá } \\
\text { 1558-[1671] }\end{array}$ & $\begin{array}{l}\text { Melchor Fuster } \\
1658-1686\end{array}$ & \multirow[b]{2}{*}{$\begin{array}{l}\text { Jaime Llosá } \\
1681-1719\end{array}$} \\
\hline & $\begin{array}{l}\text { Vicente Noguera } \\
\quad 1685-1701\end{array}$ & $\begin{array}{c}\text { José de la Torre y } \\
\text { Orumbella } \\
1671-1702\end{array}$ & $\begin{array}{l}\text { Antonio Prats } \\
1686-1706\end{array}$ & \\
\hline
\end{tabular}

Fuente: Elaboración propia

Pero ¿y la canonjía lectoral? En realidad, la bula Super universi no se había referido a ella. A juicio de la Santa Sede porque de sus funciones podían encargarse los pavordes de la seo, algunos con cátedra aneja de Teología en el Estudi General y magníficamente preparados para aleccionar sobre las Escrituras Sagradas. ${ }^{17}$

El razonamiento no convenció al cabildo valentino. Pero tampoco a la Corona, que en su intento de homogeneizar las Iglesias catalano-aragonesas al modelo castellano y mejorar al mismo tiempo el nivel de clero capitular a través de una mejor selección, perseveró en la consecución de esta última prebenda, redoblando instancias en Roma a través del embajador don Pedro de Aragón. Por él sabemos de una nueva petición al papa, en diciembre de 1664, fundada «en lo que avía dispuesto el Conçilio de Trento y de que todas las Iglesias de España, exceptuadas mui pocas y essas no de esta calidad, goçavan de los quatro canonicatos y que en aquella çiudad [de Valencia], donde ay tantos professores de letras, era más neçessario que en otras». Motivos suficientes para destinar a tal oficio la más próxima vacatura canonical y suspenderse entretanto la concesión de nuevas coadjutorías por parte del papa «para que tanto más fácil y brevemente pudiese suceder esta vacante». ${ }^{18}$

Similares instancias, con resultados igualmente nulos, se repitieron en los años siguientes a cargo ya de la reina doña Mariana de Austria. ${ }^{19}$ Ninguno de los sucesores de Alejandro VII en la cátedra petrina halló razones para dotar a la catedral de Valencia de una canonjía doctoral. Menos todavía para prescindir de los sustanciosos ingresos que suponían a la Dataría Apostólica la creación de coadjutores con derecho a

17 Epitome sive compendium... Titulus IIII De his quae spectant ad praeposituras sedis Valentinae: 59 y ss. y Ciprés de Povar, S. 1641. Origen y progresso de las pabordrías de la santa metropolitana iglesia de Valencia. Roma: Imprenta de la Cámara Apostólica.

18 ACA. Consejo de Aragón. Leg. 803: 1/71 - 1/72.

19 ACA. Consejo de Aragón. Leg. 803: 1/81. sucesión sobre determinadas prebendas. ${ }^{20} \mathrm{Ni}$ siquiera visto el panorama ofrecido por el cabildo metropolitano, alarmante a tenor de las informaciones conocidas en 1669:

... es digno de llorar con lágrimas de sangre ver un cabildo como este todo llano de muchachos, muchos dellos hijos de personas viles y casi todos sin virtud ni letras, con que ver una processión causa risa y provoca a desprecio ver un cabildo que en algún tiempo fue de tanto lustre. Y si no fuera por los dos de los tres canónigos de oficio que ay, y uno u dos capitulares, la iglesia se viera no sólo deslucida, sí postrada, fuera de que en casi todas estas cojutorías ay peligro y en algunas se han cometido execrables simonías. ${ }^{21}$

\section{EL GRAN TRANCE DE 1671-1673}

Aunque él mismo lo había sido de su tío, nunca tuvo coadjutor el canónigo don Ximeno Pérez Garrigues, fallecido el 16 de junio de 1671.22 Nada impidió, pues, que el nuevo arzobispo de Valencia don Luis Alfonso de los Cameros, otrora inquisidor y juez de la Regia Monarquía en Sicilia, donde había intervenido con determinación en el apaciguamiento de las graves revueltas allí acaecidas antes de caer prisionero de los franceses y ocupar posteriormente los obispados de Patti y Monreale, dispusiera de la primera vacante canonical de su pontificado, producida además durante un

20 Y es que «por una coadjutoría que no pasaba de los 60 escudos anuales de valor, incluyendo los frutos ciertos e inciertos, se pagaban 100 escudos de componenda, más 94 escudos por la expedición de la bula, más otras tasas, que montaban con la componenda en total 268 escudos, o sea, casi el 450 por 100 del valor de la coadjutoría. Y ésta era la que menos costaba». (Aldea Vaquero 1961). Véase Irigoyen López 2001: 49-64.

21 Informe confidencial del doctor Juan Bautista Godoy al vicecanciller del Consejo de Aragón. ACA. Consejo de Aragón. Leg. 803: 102.

22 ACV. 691, Llibre de possessions: 135v. 
mes de competencia episcopal ${ }^{23}$. Y lo haría para conferirla a don Garcerán de Mercader y Cervellón, del linaje nobiliario de igual apellido muy vinculado a la mitra. ${ }^{24}$

Quizá esperara el cabildo ser consultado después de que los prelados sucedidos a lo largo de las últimas dos décadas - fray Pedro de Urbina, don Martín López de Hontiveros y don Ambrosio Ignacio de Spínola y Guzmán - le hubieran otorgado un protagonismo en la vida diocesana del que había carecido durante la primera mitad de la centuria. ${ }^{25} \mathrm{O}$ al menos un candidato que no suscitara rechazo entre los canónigos, cuya vinculación con las más ilustres familias regnícolas había llevado hasta las entrañas de la seo las bandositats que enfrentaban a buena parte de la sociedad valenciana y en las que el número y calidad de los clérigos implicados era considerable. ${ }^{26}$

Como quiera que fuese el asunto desató las tensiones hasta entonces contenidas entre capítulo catedralicio y arzobispo. Porque el primero planteó un órdago al segundo negándose a conferir a Mercader la posesión de la última vacante en virtud de las disposiciones tridentinas respecto a las canonjías lectorales, el patrocinio de estas por parte de la Corona y el precedente de las demás prebendas de oficio ya establecidas con el beneplácito de anteriores ordinarios. ${ }^{27}$ El día 18 de junio eran despachadas pese a todo las correspondientes letras episcopales de colación en favor de don Garcerán, ordenándose al cabildo le diera posesión en el término de veinticuatro horas y bajo pena de entredicho y 500 ducados de sanción. ${ }^{28}$

Resistiéronse a hacerlo los canónigos y apelaron contra la medida, primero ante la Real Audiencia, pronto inhibida del asunto; ${ }^{29}$ y luego ante la reina gobernadora doña Mariana de Austria, con la esperanza en esta ocasión de que el prelado suspendiese cualquier procedimiento a la espera del pronunciamiento regio..$^{30} \mathrm{El}$ hecho provocó la repulsa de Cameros, hasta el extremo de protagonizar un encontronazo con el vicesíndico capitular don José Just ${ }^{31}$ y el nuevo doctoral don José de la Torre y Orumbella, ${ }^{32}$ a quienes echó de su palacio entre insultos «intentando con la muleta que tenía en su mano executar el golpe en [los] dos sacerdotes»..$^{33}$

Faltó tiempo al cabildo para poner el suceso en conocimiento del virrey de Valencia, a la sazón don Vespasiano Gonzaga, conde de Paredes, a la par que comisionaba al deán y canónigo don Francisco Fenollet ${ }^{34}$ para desplazarse

23 A la espera de una biografía sobre este prelado se remite a Olmos Canalda 1949: 213-214, y Pérez Villanueva y Escandell Bonet 2000: 1.219 .

24 Esquerdo 2001: II, 343.

25 Callado Estela 2010, e. p.; García Sánchez 2016: 18-88.

26 Nos ocupamos del asunto en Callado Estela 2003, 2012a, 2014.

27 ACA. Consejo de Aragón. Leg. 781: 6/78.

28 ACA. Consejo de Aragón. Leg. 781: 6/11.

29 ACA. Consejo de Aragón. Leg. 781: 6/14

30 ACA. Consejo de Aragón. Leg. 803: 1/21.

31 Coadjutor de su tío Urbano López desde 1640, le había sustituido al frente del canonicato en 1652. Falleció en 1680. ACV. 691, Llibre de possessions: 119.

32 En 1671 y por oposición se había posesionado de esta canonjía doctoral que ejerció hasta su resignación en 1702 para ocupar el obispado de Orihuela. En él se mantuvo el resto de sus días, concluidos el año 1712 (Vilar 1981: IV, III, 293-300).

33 ACA. Consejo de Aragón. Leg. 781: 6/69.

34 Al que no debe confundirse con su tío de igual nombre, también deán y canónigo y del que fue coadjutor hasta hacerse él mismo con la titularidad de ambas prebendas en 1657. En 1701 murió. ACV. 691, Llibre de possessions:123v. a la corte y representar a la soberana los excesos del arzobispo a fin de que

... se abstenga de estos proçedimientos imitando a sus predecessores, que haviendo sido tan grandes siempre han procurado favorecer al cabildo, y más quando siempre ha sido nuestro blanco el procurar el mayor respeto y veneraçión a los arçobispos que han sido de esta Yglesia y al que oy lo es defendiendo las preheminencias de la mitra a nuestras expensas quando se ha offrecido la occasión. ${ }^{35}$

Acto seguido los capitulares romperían oficialmente con don Luis Alfonso de los Cameros. En señal de protesta dejarían de visitarle en los habituales actos protocolarios, así como de asistirle y auxiliarle en oficios y ceremonias religiosas. ${ }^{36}$

Para entonces habría llegado una carta real a la capital valentina instando al prelado a que asignase de inmediato al oficio lectoral el canonicato vaco en la catedral. A la gratitud del cabildo por esta determinación se sumaría la de los estamentos del Reino ${ }^{37}$ y los munícipes,

... atenent al consuelo universal deste Reyno y a les poques prevendes que y a en aquell per a sos fills per no poder-ne tenir en altres que y regoneixent la honra tan gran que alcansà aquesta ciutat, per ser la més interessada en que sos fills se animen a estudiar per a aspirar a meréixer premis de tan gran consideració, a pareguten primer lloch rendir a vostra magestat les gràcies per la resulusió tan faborable als fills de aquesta ciutat. ${ }^{38}$

Misivas a las que replicó el arzobispo con un par de escritos fechados el 28 de junio y el 2 de julio. ${ }^{39}$ Por medio de ellos negaría su competencia para proceder según lo ordenado sin autorización de la Santa Sede, a la que reiteradamente se había recurrido desde finales de la década pasada obteniendo siempre el silencio por respuesta. El ejemplo de las anteriores afectaciones canonicales no venía al caso, aseguraba. Especialmente la doctoral, pues había sido una decisión de la Corona valiéndose del hueco ocasionado por la promoción episcopal de don Francisco de Rojas a la diócesis de Tarragona, tras la cual algunos otros se habían producido sin tener efecto cuanto ahora se intentaba. Tampoco era pertinente el conocido capítulo de Trento, que no afectaba a la seo valentina con quince pavordías ocupadas en la práctica de la lectura sacra, fuera en la propia iglesia mayor, donde disfrutaban de un beneficio, o en la Universidad, al frente de las cátedras que regentaban. Al proveer la vacante canonical en don Garcerán Mercader decía Cameros haberse limitado a cumplir con su obligación como ordinario. Conferida estaba ahora y ya nada podía hacerse salvo darse posesión de ella a su beneficiario. Aunque insistiera en lo contrario el cabildo, manipulado por uno de sus cabecillas, de la noble casa de Guerau de Pinós - mal avenida al parecer con los Mercader- y a quien el prelado trataba de meter en cintura con ánimo de pacificar al clero catedralicio enfrentado por mil cuitas internas. Hablamos del vicario capitular y síndico del estamento eclesiástico del Reino don Gaspar Guerau

35 ACA. Consejo de Aragón. Leg. 781: 6/78.

36 ACA. Consejo de Aragón. Leg. 781: 6/79.

37 ACA. Consejo de Aragón. Leg. 781: 6/2.

38 ACA. Consejo de Aragón. Leg. 781: 6/5 - 6/3.

39 ACA. Consejo de Aragón. Leg. 781: 6/5 - 6/7 y 6/17. 
de Arellano, hermano del Maestre Racional de Valencia. ${ }^{40}$ Sin olvidar a otro canónigo de infausta fama al que antes se hacía referencia, don José de la Torre y Orumbella:

El primero hombre tan inquieto como se conoció governando este Reyno el virrey marqués de Camarasa y siendo arzobispo don Martín de Ontiveros, pues fue necessario entonces desterrarle deste Reyno, siendo sujeto apríssimo para inquietudes y para engañar y empeñar a sus colegas. El otro es nuevo en su canonicato doctoral; hombre moço y de cortas experiençias, muy presumido y enemigo de novedades. ${ }^{41}$

A mediados de julio el virrey conde de Paredes confesaba a la soberana su incapacidad para hacer entrar en razón a don Luis Alfonso de los Cameros, quien seguía sin cumplir las reales órdenes recurriendo ahora a Roma para dar a su protegido la prebenda cuya posesión le negaba el cabildo. ${ }^{42}$ Todo lo cual preocupaba seriamente al noble, «no pase [la materia] a desazones por la desazón de los parientes del proveído y de los canónigos»..43

Doña Mariana de Austria trataría de evitarlo por todos los medios. De un lado escribiendo a su embajador en el Santa Sede, el cardenal Johann Eberhard Nithard, para impedir cualquier declaración pontificia en el sentido pretendido por la mitra. ${ }^{44} \mathrm{Y}$ del otro apercibiendo al arzobispo por vez segunda instándole a que obedeciera sin más dilación la regia voluntad. ${ }^{45}$

Los últimos acontecimientos agotaron la paciencia del capítulo catedralicio. Así lo revela el memorial de agravios compuesto contra los abusos episcopales silenciados hasta entonces en deferencia a la primera autoridad eclesiástica del Reino de Valencia. Porque según los canónigos, el prelado no estaba sino ajustando cuentas con ellos. De hecho acababan de negarle el uso de los ornamentos pontificales propiedad de la seo después de no haber devuelto algunos de ellos prestados a su llegada a la diócesis. Habíanle reprochado también la introducción en el culto divino de ciertas novedades inapropiadas, como concluir los oficios divinos pasado el mediodía por presentarse en el coro siempre tarde y las más de las veces en silla de manos hasta el mismo altar. Peor todavía era que durante estas celebraciones, a la vista de toda la feligresía, "se mandava hazer ayre con un ventallo muy descompassado", de plumas y afeminado. Tampoco en lo económico parecía el cabildo estar satisfecho con Cameros. Primero por adeudar a la iglesia mayor 1.500 libras cargadas sobre la mesa arzobispal a favor de su fábrica, según bula original casualmente extraviada por la curia diocesana. Y segundo por dar cobertura a los beneficiados de la

40 Esquerdo 2001: 363-364. A los diecisiete años se había incorporado don Gaspar al cabildo de la catedral como coadjutor de su tío Martín Bellmont. El fallecimiento de este le llevó a ocupar el canonicato en propiedad el año 1643, auxiliándose desde entonces por varios coadjutores. Falleció en 1701. ACV. 691, Llibre de possessions: 133. Junto a sus oficios eclesiásticos ejerció también como embajador del Reino de Valencia y portavoz de sus reivindicaciones ante la corona (Guía Marín 1975 y García Martínez 1991: 182, 184, 190 y 196-199.

41 ACA. Consejo de Aragón. Leg. 781: 6/5 - 6/7.

42 ACA. Consejo de Aragón. Leg. 781: 73/5.

43 ACA. Consejo de Aragón. Leg. 781: 6/131.

44 Las instrucciones al respecto en ACA. Consejo de Aragón. Leg. 781: 6/12

45 ACA. Consejo de Aragón. Leg. 803: 1/122. catedral en sus reivindicaciones pecuniarias sobre las rentas canonicales. ${ }^{46}$

Tan rápido como contundente resultó el descargo del arzobispo contra tales imputaciones, fundadas en su opinión «no en agravios que los canónigos hayan recibido, sino en lo que ellos me han hecho; o por mejor decir, en las faltas y desatenciones que han usado conmigo, sino delitos, que han cometido contra mi». Prácticamente desde el mismo momento de su nombramiento juraba haber padecido el desprecio de los canónigos, quienes ya no le habían enviado la embajada de enhorabuena acostumbrada en estos casos. Jamás se lo había afeado, sin embargo. Por el contrario venía acudiendo en su ayuda siempre que lo necesitaban. ¿Acaso olvidaban la donación episcopal de 8.000 ducados para la capilla mayor de la seo que tanto le habían agradecido quienes ahora le criticaban...? ${ }^{47}$

Fuera así o no a comienzos de agosto Cameros hizo pagar al cabildo su conducta en las personas de don Gaspar Guerau de Arellano y don José Just, cesados fulminantemente en las responsabilidades que ejercían por delegación de la mitra. A ellos se sumó el canciller del Estudi General don Laudomio Chavert. ${ }^{48}$ Los tres acusados de incumplir con las obligaciones propias del oficio para el que habían sido designados,

... parece y aún es evidente - justificó el preladoque no sólo han faltado a infidelidad que me debían en la administración de los oficios que administran en mi nombre y como procuradores míos, sino que han passado a incurrir en una culpa tan de mala condición que no quiero darle nombre. Ésta ha sido la de haverse valido en differentes ocasiones de mis mesmos poderes o nombramientos obrando con ellos y en virtud de ellos contra mí. ${ }^{49}$

Mientras los represaliados intentaban probar sus derechos ante la Real Audiencia serían sustituidos por otros tantos clérigos, sino ajenos al capítulo catedralicio incorporados a él hacía poco. El caso sin ir más lejos del canónigo don Marcos Antonio Gombau, nuevo síndico capitular; 50 don Pedro de Albelda, coadjutor todavía de su tío - el también canónigo don Aurelio- y desde ahora primera voz del estamento eclesiástico; ${ }^{51}$ y el pavorde doctor Eusebio Falcó, oficial de causas pías del arzobispado y al frente de la Universidad en adelante. ${ }^{52}$

La noticia sentó a rayos al cabildo. Habría por supuesto nuevas críticas contra los modos del arzobispo, aunque también para sus subalternos recién electos. El peor parado de todos fue Gombau, hijo del regente de la Audiencia, de natural fogoso y que, «además de ser moderno, sus

46 ACA. Consejo de Aragón. Leg. 781: 6/47 - 6/ 48.

47 ACA. Consejo de Aragón. Leg. 781: 6/52 - 6/61.

48 Titular de un canonicato en la catedral de Valencia desde 1655 falleció el año 1704. ACV. 691, Llibre de possessions: 121v.

49 ACA. Consejo de Aragón. Leg. 781: 6/57.

50 Había sustituido en 1667 al canónigo Miguel Jerónimo de Ystela, del que fue coadjutor. Murió pronto, en 1677. ACV. 691, Llibre de possessions: 131.

51 No se posesionaría de una canonjía en propiedad hasta la desaparición de don Aurelio de Albelda en 1676. En ella se mantuvo hasta su fallecimiento a comienzos de la posterior centuria.

52 Doctor en Teología y cánones, catedrático de Prima y cancillerjuez de competencias del Reino y autor de varias obras impresas, murió en 1677. Felipo Orts, A. y Callado Estela, E. 2016: 219. 
extravagancias son de género que ni el arçobispo las ignora ni nosotros, por collega y hermano nuestro, las referimos". A todos se hizo evidente el 8 de agosto. En aquella fecha el muchacho irrumpió violentamente en una junta capitular reunida a sus espaldas en la catedral. Casi llegó a las manos con los prebendados allí presentes, entre ellos los depuestos Guerau, Just y Chavert. Según algunas informaciones, apenas pudo templarle la mediación del ejemplar canónigo Félix Miró de Ayala, ${ }^{53}$ pues

.. se descompuso con él con descompasadas voçes y palabras. Díxole el canónigo Miró se sosegase porque havía poco que havía dicho misa y por su estado no le podía responder como devía, ohído lo qual creció la descompostura de don Marcos diziéndole que fuera le guardaría y le buscaría, repitiendo estas razones por dos o tres vezes y aún dando demonstraciones de quererle allí envestir; y huviera allegado a efecto si no se huvieran interpuesto y detenido a don Marcos los demás canónigos y en especial el canónigo Pedro [de] Albelda, el qual entró también en cabildo poco después que don Marcos para assistirle [...]. Pero ningunas razones bastavan a persuadirlo, antes bien continuava en dezir tales palabras que, a los hombres más pacíficos y dotados de más virtud, les pusieran conocidamente en ocaçión de perderse. Pero fue providencia divina disponer de tal suerte sus ánimos que ni lo ocasionado de sus palabras ni lo descompuesto de sus acciones pudo insitarle. ${ }^{54}$

Lo peor podría haber ocurrido fuera de la sala de reuniones, con los beneficiados al borde del motín a decir de estos mismos testimonios:

Al ruido de las vozes, el beneficiado mosén Joseph Insa hiva por la iglesia convocando los demás clérigos y diziéndoles fuesen a asistir a don Marcos, que era orden del señor arçobispo, con que llegaron a la puerta del cabildo muchos de ellos y estuvieron aguardando se travase el empeño entre los canónigos para entrar a proseguirle y don Gerónimo Mercader y don Luis Figuerola estuvieron en el mismo puesto y se entiende que para lo mismo [...].

La investigación de los sucesos corrió por cuenta de la lugartenencia general del Reino. Media docena de testigos depondrían sus informaciones sobre tales en presencia de los oidores de la Audiencia. ${ }^{55}$ Entretanto don Luis Alfonso de los Cameros se apresuró a negar ante el virrey cualquier responsabilidad en lo acontecido, bastante menos tumultuoso de lo que se decía y en ningún caso con riesgo para la paz pública. Tampoco había sido cosa de Gombau según sabía, sino de don Gaspar Guerau de Arellano y sus adláteres, «los verdaderamente culpados en lo que passó». ${ }^{56} \mathrm{Y}$ en idéntico sentido insistiría a la reina gobernadora el arzobispo. Para él no había eclesiástico en la diócesis valentina tan sedicioso

53 Canónigo de la catedral de Valencia desde 1664 y hasta 1673, fecha de su óbito. ACV. 691, Llibre de possessions: 136.

54 ACA. Consejo de Aragón. Leg. 781: 6/41.

55 Informació ex officio rebuda per lo magnígich Ysidoro Aparici Gilart, doctor del Real Consell civil y criminal en la present ciutat de València. ACA. Consejo de Aragón. Leg. 781: 6/94. También los canónigos recopilaron sus propios testimonios, en este caso para probar ante el Justicia de la capital su derecho a poder resunirse como particulares sin previa convocatoria del vicario capitular. ACA. Consejo de Aragón. Leg. 781: 6/82.

56 ACA. Consejo de Aragón. Leg. 781: 6/59. como el destituido vicario capitular, fomentador de bandos y bandoleros, responsable de varios homicidios, amancebado con una mujer casada - cuyo esposo había jurado muerte a ambos - y acostumbrado a hacer y deshacer a su antojo hasta ser reconvenido por la mitra. Por eso había puesto contra ella no solo al cabildo, sino incluso a las órdenes regulares, el estamento eclesiástico al completo y aún la Universidad y la capital entera:

.. don Gaspar ha pretendido sublevar contra mí todas estas comunidades, porque la de esta Ciudad ha engañado con pretexto de conveniencia en lo de hazer el canonicato lectoral [...]. De la mesma manera y con el mesmo pretexto pretendió sublevar el estamento eclesiástico [...]. Pretendió sublevar contra mí todos los regulares desta ciudad con pretexto de que era buena ocasión para bolver sobre la differencia que havían tenido conmigo, y ha muchos días que se ajustó en raçón de las licencias de confessar monjas [...]. Pretendió también don Gaspar con la Ciudad, con pretexto de que era buena ocasión para ello, que entrasse a ver si yo ordenava a los que no tenían beneficio y a si tolerava habitar en esta ciudad clérigos forasteros, y así, de lo uno y lo otro que fingía, resultaría daño a las impossiciones desta Ciudad [...]. Ha solicitado y está solicitando sublevar la Universidad de esta ciudad y unir con ella a esta Ciudad, sobre el pleyto que trata con los padres de la Compañía, no tanto por ser contra la Compañía quanto por entender que resultaría contra mí por una commutación de una última voluntad que yo hize a favor del Seminario de los padres de la Compañía. ${ }^{57}$

Afirmaba el prelado que el mismísimo conde de Paredes había sucumbido a los embelecos de Guerau de Arellano, contra quien nada hacía. No se entendía de otro modo que las testificaciones recopiladas con motivo de los últimos incidentes de la catedral hubieran sido a instancia suya. Las influencias de don Gaspar llegaban hasta la corte. Allí, donde Cameros conservaba importantes enemigos desde sus días como inquisidor, había enviado al canónigo don Francisco Fenollet para unirse a ellos y desacreditarle a ojos de la Corona, cuyo amparo solicitaba ahora el arzobispo...

Entre el 13 de agosto y el 9 de septiembre el Consejo de Aragón elevó a doña Mariana de Austria cinco consultas alertándole de la gravedad de los sucesos ocurridos en Valencia, la culpabilidad del ordinario en los mismos y la necesidad de amonestarle, ya que «si no se acude con breve y efficaz remedio han de resultar tales inconvenientes que pongan en conocido riesgo la quietud de aquella ciudad y aún de todo el Reyno». Tal vez debía haberse intervenido antes en la crisis que atravesaba la Iglesia valentina, cuyos orígenes se remontaban a los antiguos pleitos que, sobre rentas de administraciones y memorias pías fundadas en la catedral, mantenía el cabildo con los más de 140 beneficiados en ella residentes, "tantos que arrastran a todos los clérigos de las otras parroquias, que son más de 500, y entre ellos hay muchos de naturales bulliciosos, inquietos y tan perjudiciales», a quienes la mitra había dado alas. ${ }^{58}$

Desde luego no era lo que el Consejo de Aragón esperaba de este prelado, "tan tenacíssimo en todos los lanzes que se han offrecido que es peligroso" para el orden y estabilidad del clero. Don Luis Alfonso de los Cameros había

\footnotetext{
57 ACA. Consejo de Aragón. Leg. 803: 1/104.

58 ACA. Consejo de Aragón. Leg. 781: 6/28.
} 
olvidado por completo la ecuanimidad que exigía su dignidad, fomentando todavía más la división entre eclesiásticos a cuenta de la canonjía lectoral que litigaba con los canónigos y que enfrentaba a toda la sociedad local:

Y con la provisión del canonicato en don Galcerán Mercader [...] tiene de su parte el arçobispo aquelos cavalleros dependientes del parentesco y amistad de aquella Cassa [y] los beneficiados de la iglesia, que [...] hazen ya cuerpo y harto peligrosso en estos empeños. Por el cavildo está declarada la Ciudad y el estamento eclesiástico [...]. Y en el estamento real, que es el de la nobleza, estarán divididos, unos parientes de don Galcerán Mercader y otros y los más porque abrazará a más el parentesco del mayor número de canónigos del cabildo. ${ }^{59}$

La remoción de cargos en la seo, estamento eclesiástico y Universidad constituían por tanto el último acto de la desfachatez episcopal. Un procedimiento incuestionablemente improcedente, en las formas y en los resultados, con la designación de «los sujetos más escandalosos y más a propósito para inquietar un Reyno [que] no pudo hallarlos peores sin mucha elección». De sobra conocido era don Marco Antonio Gombau. Pero también clamaba al cielo el perfil de don Pedro de Albelda, otro joven con un amplísimo historial delictivo encumbrado por obra y gracia de la mitra a la cúspide de la representación política del clero:

... si a un mozo desta calidad se le da poder para intervenir en las Juntas del Reyno en nombre de la cabeza del estado ecclesiástico, que es el arçobispo, donde se tratan materias que tocan tanto a la virtud pública y al servicio de vustra magestad, ¿qué effectos se pueden esperar y qué juicio se puede hazer de la intención del arçobispo, quando suis antecessores [...] han acostumbrado fiar estos officios de los canónigos más antiguos y experimentados? ${ }^{60}$

En resumen tales nombramientos urgían ser revocados según el Consejo de Aragón. En el caso de Gombau además no debía quedar impune su actuación en los hechos del pasado 8 de agosto. En virtud de la potestad económica - que facultaba a la Corona para proceder por vía extrajudicial contra cualquier súbdito implicado en graves crímenes- podría desterrársele del Reino en el plazo de unos días. Respecto al arzobispo, causante en última instancia de cuanto había sucedido en Valencia durante las pasadas semanas, su amonestación era insoslayable, y «no puede el Consejo dexar de repetir quán peligrosa es su condición y quánto se necesita de hazerle entrar en conocimiento de que no se le ha de tolerar que, por sus precipitadas resoluciones, se aventure la quietud de aquel Reyno [...] y convendrá advertírselo». ${ }^{61}$ Se proponía a doña Mariana de Austria la forma de hacerlo, en persona y en la corte a ser posible:

... es de sentir el Consejo que el arçobispo merecía que vuestra magestad le mandare venir a esta corte, que es el medio más efficaz para atajar estas diferencias. Y quando vuestra magestad, por su benignidad, no inclinare a que se llame al arçobispo de manera que parezca mortificación, como se suele procurar con

\footnotetext{
59 ACA. Consejo de Aragón. Leg. 803: 1/29.

60 ACA. Consejo de Aragón. Leg. 781: 6/28.

61 ACA. Consejo de Aragón. Leg. 803: 1/32
}

otros prelados en España quando sus procedimientos piden este remedio, entiende el Consejo que [...] será bien se le escriva que vuestra magestad necessita de su persona en esta corte, porque quiere interponer su real authoridad para que se compongan las differencias que passan con su cabildo, porque de otra suerte juzga el Consejo que a de ser dificultoso el remedio. ${ }^{62}$

Solo las nuevas informaciones del virrey don Vespasiano Gonzaga sobre un principio de entendimiento entre las partes moderaría las exigencias del Consejo de Aragón, luego también la enésima llamada de atención de la monarca al prelado, el 21 de septiembre, para que se ajustara a la afectación del canonicato vacante en los términos reivindicados por el capítulo catedralicio. ${ }^{63}$ De momento sin el placet de la Santa Sede, por cuanto suponía de renuncia a futuras pensiones sobre esta prebenda a cargo de la Dataría Apostólica, sin capacidad para hacerlo en las canonjías asignadas por oposición como se pretendía con la lectoral de la catedral de Valencia. ${ }^{64}$ Ello explica que don Luis Alfonso de los Cameros se resistiera a transigir. ${ }^{65}$ Es más, mantendría en sus puestos a Falcó, Gombau y Albelda, preparados para ejercerlos a su entender en tanto los cesados no se dieran por tales desistiendo de los procedimientos judiciales iniciados contra la mitra. ${ }^{66}$

A punto de agotarse la paciencia de la Corona, el vicecanciller del Consejo de Aragón don Melchor de Navarra y Rocafull, uno de los escasos apoyos del ordinario en Madrid, planteó la posibilidad de que don Garcerán Mercader renunciara voluntariamente a ocupar la prebenda vacante a cambio de una pensión de 600 escudos sobre la diócesis, de modo que pudiera asignarse al oficio lectoral como ansiaba el cabildo aunque sin merma económica para el candidato episcopal. ${ }^{67}$ Menos coste económico para sus arcas tendrían otras dos alternativas planteadas por el propio arzobispo, en ambos casos previa gracia pontificia. La primera que Mercader consintiera la afectación una vez fallecido. La segunda que se pospusiera el asunto hasta diciembre, mes reservado a la mitra en materia de provisiones canonicales. Entonces «podrían renunciarme don Garcerán su canonicato y el doctor Isidoro Segura el arcedianato de Morviedro, que le he dado estos días, y yo trocar estas provisiones dando a don Garcerán el arcedianato y a Segura el canonicato, asignándolo para lectoral y a Segura por canónigo lectoral, que es sugeto para ello».68

La monarca aprobó esta última opción a instancias del vicecanciller del Consejo de Aragón como única solución para desatascar la situación. ${ }^{69}$ Lástima que nuevas salidas de tono del prelado alejaran cualquier posible acuerdo entre las partes.

62 ACA. Consejo de Aragón. Leg. 781: 6/28.

63 ACA. Consejo de Aragón. Leg. 781: 6/43.

64 El informe del cardenal Nithard a este respecto en ACA. Consejo de Aragón. Leg. 803: 1/125. Los resultados de sus posteriores gestiones en ACA. Consejo de Aragón. Leg. 803: 1/108.

65 ACA. Consejo de Aragón. Leg. 781: 6/44.

66 ACA. Consejo de Aragón. Leg. 803: 1/34 - 1/35.

67 ACA. Consejo de Aragón. Leg. 803: 1/33.

68 ACA. Consejo de Aragón. Leg. 803: 1/36- 1/37. Segura acababa de sustituir en el citado arcedianato a Juan Bautista Ballester. ACV. 691, Llibre de possessions: 135. Era doctor en Cánones y Leyes y pavorde (Felipo Orts y Callado Estela 2016: 246-247).

69 ACA. Consejo de Aragón. Leg. 803: 1/42. 


\section{HACIA UNA SOLUCIÓN}

A comienzos de octubre de 1672 el deán don Francisco Fenollet denunció las maniobras que en nombre de don Luis Alfonso de los Cameros se llevaba entre manos su hechura Eusebio Falcó para enfrentar al capítulo con la pavordía después de más de treinta años de concordia entre ambos colectivos. Otra afrenta para el cabildo había supuesto la designación como nuevo visitador general diocesano del rector de la parroquia de Santo Tomás Apóstol mosén Francisco Campos - con varios litigios pendientes con la catedral- en detrimento del canónigo don José Barberá, obispo auxiliar de Maronea muy crítico con las actuaciones de su superior. ${ }^{70}$ El mismo afectado invocó la intercesión de la Corona. ${ }^{71}$

A estas últimas quejas contestó Cameros de forma categórica. Entre sus atribuciones contaba poder designar tantos visitadores como estimara oportunos, sin más justificación ni explicaciones. Aunque las había en esta ocasión, dada la negligencia mostrada por Barberá en su recorrido pastoral a lo largo y ancho de la diócesis, empantanado desde hacía más de dos años pese a ocultarlo a la mitra. ${ }^{72}$

El Consejo de Aragón había escuchado bastante. Antes de finalizar el mes recomendó a la reina gobernadora un escarmiento ejemplar para el arzobispo de Valencia, cuyo ánimo era "continuar los ultrages que ha hecho al cabildo, declarando su enemiga y mala voluntad sin embargo de las órdenes que le ha remitido vuestra magestad». Lo demostraba con su inquina hacia el doctor Barberá. ${ }^{73}$ Solo la mediación de don Melchor de Navarra y Rocafull evitó probablemente este castigo, siempre y cuando el prelado llevara a buen puerto la permuta aprobada por la Corona semanas antes, con el consentimiento de los dos principales afectados, don Garcerán Mercader y el doctor Isidoro Segura. ${ }^{74}$

Para sorpresa de todos, el segundo de ellos se negó a renunciar al arcedianato de Morvedre a cambio de la canonjía del segundo destinada a lectoral, poniendo en evidencia al prelado, su amigo y bienhechor hasta entonces. A mediados de noviembre don Luis Alfonso de los Cameros se sinceraba con el vicecanciller del Consejo de Aragón:

... confieso el empeño y que a no ser yo prelado y Segura sacerdote debiera yo con la espada en la mano hazer que Segura me cumpliera la palabra o perdiera la vida. Empero siendo ambos sacerdotes, y en conseqüencia no siendo tratable ni aún imaginable llegar a esta demostración, he hecho con él todas las demostraciones que mi estado ha permitido, haviendo llegadio a apartarlo totalmente de mi gracia y a desterrarlo de mi casa y de mi comunicación y vista. ${ }^{75}$

Tampoco las presiones del virrey hicieron mudar de parecer a Isidoro Segura, aferrado a toda suerte de excusas

70 ACA. Consejo de Aragón. Leg. 781: 6/85. Doctor en ambos Derechos y canónigo desde 1645, Barberá había comenzado a ejercer como auxiliar de la mitra en 1661 y al servicio de don Martín López de Hontiveros. Murió en 1675 (Guitarte Izquierdo 1985: 59-60; Callado Estela 2012b).

71 ACA. Consejo de Aragón. Leg. 781: 6/83.

72 ACA. Consejo de Aragón. Leg. 781: 6/67.

73 ACA. Consejo de Aragón. Leg. 781: 6/84.

74 ACA. Consejo de Aragón. Leg. 803: 1/41. Intercesión que don Luis Alfonso agradeció al vicecanciller, pues una vez más «ha sido vuestra señoría elúnico medio y vía por donde la reyna nuestra señora, Dios la guarde, se ha servido de ampararme y honrarme».

75 ACA. Consejo de Aragón. Leg. 803: 1/44. calificadas de frívolas por el conde de Paredes. ${ }^{76} \mathrm{Ni}$ siquiera el ofrecimiento de una renta de 1.000 ducados extra por parte del duque de Medinaceli, deudo del prelado valentino y para quien el doctor Segura litigaba como abogado algunos pleitos sobre la Casa de Segorbe. El mismo asunto legal por cierto que obligaría a don Melchor de Navarra y Rocafull a inhibirse de ambas causas debido a un conflicto de intereses con los Medinaceli. ${ }^{77}$

El Consejo de Aragón aprovechó esta última circunstancia para arremeter otra vez contra Cameros. Puesto que la componenda en el aire había sido cosa suya, él debía sacarla adelante, empleando para ello todos los recursos al alcance de la mitra, incluso el destierro o la cárcel para su íntimo colaborador. Cualquier cosa con tal de facilitarse la pacificación de la Iglesia local, labor en la que andaba comprometida la Corona. ${ }^{78}$ En este tono escribiría también al arzobispo doña Mariana de Austria el 11 de enero de 1673, con órdenes expresas al virrey de Valencia para que «de una manera u de otra se salga deste cuidado ${ }^{79}$

Durante las semanas siguientes habría nuevas gestiones para persuadir a Isidoro Segura. ${ }^{80}$ En vista de sus escasos resultados, el conde de Paredes decidió iniciar una ronda de conversaciones a tres bandas, bajo su presidencia y con la participación de mitra y cabildo, prolongadas a lo largo de varios meses con escasos avances. ${ }^{81}$ Mucho tendría que ver en ello la postura irreductible del arzobispo frente a los canónigos, a quienes planteó entre otras exigencias unas públicas disculpas a cuenta del padecimiento infligido; la posesión inmediata de la prebenda origen de esta crisis por parte don Garcerán Mercader, dejando en suspenso su asignación a lectoral hasta el pronunciamiento de Roma; y la renuncia a cualquier reivindicación sobre los oficios eclesiásticos de vicario capitular, voz del estamento eclesiástico y canciller del Estudi General, para los cuales se comprometía a buscar otros candidatos. ${ }^{82}$

El segundo de los puntos constituyó el principal escollo de las negociaciones, al añadir el capítulo catedralicio un nuevo antecedente a los ya planteados para apoyar sus reivindicaciones. Durante el pontificado del Patriarca don Juan de Ribera había sido afectada como penitenciaria una canonjía vacante sin licencia apostólica previa, como en Córdoba, Cuenca, Sigüenza y otras muchas catedrales de la Monarquía. ${ }^{83}$ La reina hizo suyo este parecer, participándolo a don Luis Alfonso de los Cameros a mediados de marzo:

Porque según lo dispuesto por el sagrado concilio de Trento y observançia subseguida en las Iglesias de España, pueden los prelados hazer estas afectaciones sin que sea necessario indulto apostólico, como lo executó el Patriarcha don Juan de Ribera siendo arçobispo de essa ciudad en la prebenda penitençiaria, me ha pareçido deziros que, si pudiéredes ajustar vuestro
76 ACA. Consejo de Aragón. Leg. 803: 1/15
77 ACA. Consejo de Aragón. Leg. 803: 1/43.
78 ACA. Consejo de Aragón. Leg. 803: 1/63.
79 ACA. Consejo de Aragón. Leg. 803: 1/62.
80 ACA. Consejo de Aragón. Leg. 803: 1/54.
81 ACA. Consejo de Aragón. Leg. 781: 41/1.
82 ACA. Consejo de Aragón. Leg. 803: 1/51.
83 ACA. Consejo de Aragón. Leg. 803: 1/60. Extremo confirmado por el Consejo de Aragón ACA. Consejo de Aragón. Leg. 803: 1/115 y $1 / 118-1 / 119$. 
dictamen al exemplar que se allega en essa misma Iglesia, seré muy servida en que lo executéis así. ${ }^{84}$

Como cabía esperar el arzobispo restó validez a estos argumentos, pero ante doña Mariana de Austria directamente y no según lo acostumbrado, es decir a través del Consejo de Aragón, cuya hostilidad hacia él - vicecanciller al margen - parecía manifiesta. Para el prelado, su antecesor en la mitra valentina había dispuesto sobre una prebenda vaca y la actual estaba proveída en don Garcerán Mercader. Además aquel canonicato de oficio estuvo sin efecto real hasta su aprobación por Alejandro VII. Por último el modo de proceder con una penitenciaria nada tenía que ver en el caso de una lectoral a tenor del concilio de Trento. ${ }^{85}$ Así que suplicaba a la soberana:

\begin{abstract}
... se sirva escusarme vuestra magestad en lo que no he podido escusar, mayormente en lo que me obliga la conciencia y reputación, demás de faltar la possibilidad que quien, como yo, ha puesto tantas veces la vida por el real servicio como la pondré y perderé siempre que fuere menester, fuera muy poco hazer la affectación de que se trata si fuesse possible, aunque tan desmerecida de los canónigos como no necessaria a esta Santa Iglesia. ${ }^{86}$
\end{abstract}

No iba a concedérsele tal satisfacción al ordinario, le aclaró la reina gobernadora el 22 de julio sin añadir nada nuevo a lo ya dispuesto. ${ }^{87}$ Tampoco parecía tener más qué decir el Consejo de Aragón, sobre todo después de que la Corona le asignara tres miembros del Consejo de Castilla -don Gil Castejón, don Lorenzo Santos y don Alonso Llanos- para discernir más y mejor sobre esta materia, algo sin precedentes aún en las peores coyunturas políticas vividas desde su creación. ${ }^{88}$

Llegados a este punto quiso el destino dar un vuelco a la situación. El 22 de septiembre de 1673 fallecía repentinamente el canónigo Félix Miró de Ayala. ${ }^{89}$ Adelantándose a la provisión de la vacante, el lugarteniente general del Reino sugirió a los actores implicados fuera esta la destinada en la catedral de Valencia a la lectura de la Sagrada Escritura, en lugar de la recaída en don Garcerán Mercader. Vendría bien en ello el cabildo metropolitano. Y también el arzobispo, a quien correspondía cubrir la prebenda por ser un mes a él reservado. ${ }^{90}$

Ambas partes volverían a sentarse a negociar a través de sus representantes para la ocasión, los canónigos don Gaspar Guerau de Arellano y el doctor Cristóbal Marco ${ }^{91}$ en

84 ACA. Consejo de Aragón. Leg. 803: 1/61.

85 ACA. Consejo de Aragón. Leg. 803: 1/91.

86 ACA. Consejo de Aragón. Leg. 803: 1/48 - 1/49.

87 ACA. Consejo de Aragón. Leg. 803: 1/99.

88 Son palabras del propio Consejo de Aragón a la monarca, pues «será ésta la primera vez en que desde la formazión del Consejo se hayan visto nombrados asociados para materia de govierno y política, y sería de sumo dolor para el Consejo el pensar que pueda ser de la real intención de vuestra magestad el alterar la forma con que se ha regido y governado este Consejo desde que tuvo origen", porque "haviendo ocurrido en este siglo y en el passado negozios de la mayor importanzia jamás se han nombrado ministros de otros Consejos». ACA. Consejo de Aragón. Leg. 781: 6/103 - 6/104.

89 Véase nota 52.

90 ACA. Consejo de Aragón. Leg. 781: 6/107.

91 Coadjutor del canónigo Vicente Calbet desde 1653, al que sustituyó al frente de su prebenda en 1660 hasta su muerte, sobrevenida en 1675. ACV. 691, Llibre de possessions: 120v. el caso del capítulo; y el vicario general don Pedro Gregorio de Antillón ${ }^{92}$ y el pavorde Eusebio Falcó por parte de la mitra. ${ }^{93}$ Un quinto personaje de sinpar reputación, escogido por el conde de Paredes y por todos aceptado, haría las veces de árbitro. Ni más ni menos que Domingo Sarrió, titular de un beneficio eclesiástico en la seo además de bibliotecario capitular cuya fama de santo le había valido su inclusión en varias ternas episcopales. ${ }^{94}$

Lo cierto es que el venerable Sarrió acreditaba una dilatada experiencia como mediador en conflictos de toda clase, el más reciente entre los labradores de la Huerta y las autoridades municipales, que había puesto en jaque la capital del Reino. ${ }^{95} \mathrm{Al}$ igual que en aquellos, consiguió en menos de un mes cuanto nadie había logrado hasta entonces. El mismo lo escribió al virrey restando importancia a su labor:

Ha parecido muy de mi obligación dezir a vuestra excelencia que todas las diferencias quedan ajustadas tanto a satisfación del señor arçobispo como a contentamiento del illustre cabildo y canónigos [...]. Y en mi sentir, sin especial asistencia de Dios y de su Madre Santíssima, no podía haverse logrado sucesso tan importante ni tan a contentamiento de todos. ${ }^{96}$

En virtud del acuerdo suscrito entre las partes, a don Garcerán Mercader se le daría posesión de su prebenda en la seo a cargo de los canónigos. La mitra consentiría a cambio la afectación de la última canonjía vacante para el oficio lectoral, sin coadjutor y con cláusula expresa de que «el provisto tendría las calidades para poder cumplir desde luego con la lectura y que sería de prendas y expedición para el manexo de de negocios»; su nombre Eusebio Falcó. En otro orden de cosas los actuales vicario capitular, voz del estamento eclesiástico y canciller de la Universidad cesarían en sus puestos, mientras los anteriores renunciaban a cualquier pretensión jurídica sobre los mismos, introducida en la Real Audiencia u otros tribunales. Aunque entre todos ellos estarían los nombres de los futuros ministros, escogidos por cuenta del arzobispo y de acuerdo con el capítulo catedralicio. Al menos el de don Laudomio Chavert y don Marcos Gombau para el Estudi General, el primero por principal y el segundo para ausencias y enfermedades del anterior; y en igual sentido don Gaspar Guerau de Arellano y don Pedro de Albelda para el estamento. Como nueva incorporación, solo la del canónigo don Tomás Antonio Corbí en calidad de vicario. Aún habría más muestras de la buena disposición entre los suscribientes de este arreglo. Por una parte el cabildo, que había recusado a la curia episcopal como juez competente en su litigio con los beneficiados, reconoció a esta para la resolución de conflictos en primera instancia. De otro lado el prelado dejó abierta la posibilidad de librar

92 Este ilustre turolense había estudiado Leyes y Cánones en la Universidad de Huesca, de cuyo Colegio de Santiago fue becario, doctorándose parece en Gandía. Como vicario general del arzobispo Cameros ejerció entre 1672 y 1675 . En esta última fecha tomó posesión del cargo de racionero en El Pilar de Zaragoza. Fue también vicario general de Toledo y canónigo de la catedral cesaraugustana antes de su promoción al episcopado como obispo de Huesca, donde falleció en 1707 (Esteban 2010: 149-156).

93 ACA. Consejo de Aragón. Leg. 781: 6/16.

94 Jordán Selva 1677.

95 Callado Estela 2013.

96 ACA. Consejo de Aragón. Leg. 803: 1/26. 
a la seo la pensión de 1.500 ducados adeudados a la fábrica catedralicia. ${ }^{97}$

El 8 de octubre casi todos los puntos convenidos se habrían ejecutado ya. ${ }^{98}$ Una solemne recepción entre don Luis Alfonso de los Cameros y el pleno capitular hizo oficial la reconciliación, dejando anotado los canónigos: «Quedamos gozosíssimos con tan feliz sucesso, viendo restituida la paz y unión con nuestro prelado que tanto hemos deseado "..$^{99}$

Siete después el doctor Falcó se posesionaba de la canonjía asignada a la lectura de la Sagrada Escritura, que Roma continuó sin reconocer en las condiciones esperadas por Corona, mitra y cabildo. Todavía a la muerte de su titular en julio de 1678 seguía sin hacerlo. Con el refrendo de la ciudad de Valencia, ${ }^{100}$ los estamentos del Reino ${ }^{101}$ y los propios canónigos, ${ }^{102}$ Carlos II recordó el asunto al papa Inocencio XI a través del embajador de España en la Santa Sede don Gaspar Méndez de Haro, marqués del Carpio. ${ }^{103}$

Nadie esperaba que el pontífice encontrara un aliado en el nuevo arzobispo del lugar fray Juan Tomás de Rocabertí, exmaestro General de la orden de Predicadores y catedrático de Teología durante varios años en la Universidad valentina, buen conocedor por tanto del nivel académico de esta institución. ${ }^{104}$ El prelado cuestionó por ello la existencia de una prebenda canonical dedicada a las Escrituras, cuando los pavordes podían encargarse de tales. Aceptaba pese a todo la afectación de la misma y su provisión por oposición, a cuenta de Roma o la mitra pero nunca del capítulo catedralicio:

... Combenimos en que se afecte la prevenda. Diferenciamos en que el cavildo y arçobispo, regulándose por votos, sin que el arçobispo tenga sino solamente una boz. La inteligencia del Concilio dista desta forma, porque lo que manda es que afecte la prevenda [a la] primera vacatura, que se comboquen con editos los opositores y concurriendo al examen se provea en el más digno. Más esta provisión se a de hacer por su santidad, en su mes, y por el arçobispo en el suyo, elixiendo el pontífice y el arçobispo libremente en el mes que le toca sin dependencia del cabildo. ${ }^{105}$

Esta posibilidad fue rechazada de plano por los canónigos, para quienes un examen en condiciones como las exigidas por el padre Rocabertí favorecería a los opositores afines a la mitra en contra de los demás, lo cual debía evitarse a toda costa. ${ }^{106} \mathrm{Si}$ no en la presente vacante, que la Santa Sede podía proveer directamente por corresponderle el mes reservado, al menos para la siguiente. ${ }^{107}$ Así lo enten-

\footnotetext{
97 ACA. Consejo de Aragón. Leg. 803: 1/26.

98 Entre ellos la posesión de don Garcerán Mercader el mismo día 8. Como canónigo viviría hasta su desaparición en marzo de 1680. ACV. 691, Llibre de possessions: 135v.

99 ACA. Consejo de Aragón. Leg. 803: 1/25.

100 ACA. Consejo de Aragón. Leg. 803: 1/136.

101 ACA. Consejo de Aragón. Leg. 803:. 1/132.

102 ACA. Consejo de Aragón. Leg. 803: 1/113.

103 Debería solicitar el noble con carácter de urgencia «a su santidad sea de su agrado se afecte [esta canongía] a lección de Sagrada Escritura y se provea por oposición para que los sugetos que la ocupan sean dignos de ella y se logre el consuelo de dicha santa iglesia». ACA. Consejo de Aragón. Leg. 803: 1/128.

104 Callado Estela 2007.

105 ACA. Consejo de Aragón. Leg. 803: 1/133.

106 ACA. Consejo de Aragón. Leg. 803: 1/137.

107 ACA. Consejo de Aragón. Leg. 803: 1/139.
}

dió también el monarca, que en diciembre del mismo año instó a su embajador en Roma a realizar «todas las diligencias que combengan a fin de que se probea esta canongía en la forma ordinaria como lo suplica el cabildo». ${ }^{108}$

Aunque tarde Inocencio XI se plegó a la regia voluntad, equiparando en julio de 1681 la canonjía lectoral de la seo valentina a las otras tres de oficio ya instituidas. ${ }^{109}$ Los exámenes para cubrirla tendrían igual formato y estructura, en este caso sobre los contenidos de la Biblia que debían defender los aspirantes, necesariamente doctores en Teología como el pavorde Jaime Llosá. ${ }^{110}$ Él fue quien se impuso y tomó posesión de la plaza el 15 de julio siguiente. ${ }^{111}$

La catedral de Valencia quedaba así incorporada a la mayoría de Iglesias de la Monarquía en las que, sobre todo a partir del Concilio de Trento, habían ido asentándose con diferentes ritmos y problemáticas estas nuevas prebendas, que mucho antes de enfrentar a los opositores en ellas interesados habían supuesto otro motivo más para el antagonismo entre cabildos y obispos postridentinos. Una contienda en la que el episcopado contó con la anuencia de la Santa Sede, que paradójicamente en vez de allanar el camino a la aplicación de las disposiciones conciliares en esta materia lo entorpeció cuanto pudo como en el caso analizado, sino para impedir los perjuicios políticos y económicos derivados de la forma de provisión de tales oficios canonicales, al menos para amortiguarlos o siquiera posponerlos. La intervención de una tercera instancia de poder, se ha visto en la sede valentina, complicó más si cabe la situación. Porque la Corona, con independencia de su afán por reformar y ordenar los capítulos eclesiásticos, pretendía en el fondo ponerlo bajo su administración y control, lo que no conseguiría del todo en esta diócesis ni en ninguna otra hasta el Concordato de $1753 .{ }^{112}$

\section{BiBLIOgRAFÍA}

Aldea Vaquero, Q. 1961. Iglesia y estado en la España del siglo XVII. Santander: Universidad Pontificia de Comillas.

Barrio Gozalo, M. 2010. El sistema beneficial de la Iglesia española en el Antiguo Régimen (1475-1834). Alicante: Universidad de Alicante.

Callado Estela, E. 2000. Iglesia, poder y sociedad. El arzobispo de Valencia fray Isidoro Aliaga. Valencia: Biblioteca Valenciana.

Callado Estela, E. 2003. Inmunidad eclesiástica y delincuencia en el siglo XVII. Los arzobispos de Valencia y la pacificación del reino (1612-1699). Valencia: Biblioteca Valenciana.

Callado Estela, E. 2007. Por Dios y por el rey. El Inquisidor general fray Juan Tomás de Rocabertí. Valencia: Alfons el Magnànim.

Callado Estela, E. 2010. Tiempos de incienso y pólvora. El arzobispo fray Pedro de Urbina. Valencia: Biblioteca Valenciana.

Callado Estela, E. 2011. «El Patriarca Ribera y el clero catedralicio valentino», en E. Callado Estela (coord.), Lux totius Hispaniae. El Patriarca Ribera cuatrocientos años después II: 337-370. Valencia: Universitat de València.

108 ACA. Consejo de Aragón. Leg. 803: 1/140.

109 «[...] ab bulla datta Romae, apud Sanctum Petrum, undecimo kalendas iunii anno Incarnationis Domininicae 1681» (ACV. 691, Llibre de possessions: 140).

110 Doctor en Teología desde 1663, había obtenido su primera pavordía en 1669 y en 1673 la segunda, a la que renunció el 18 de julio de 1681 para encargarse de la canonjía lectoral. Muerto en 1719, dejó inéditas varias obras (Felipo Orts y Callado Estela 2016: 231-232).

111 ACV. 691, Llibre de possessions: 140.

112 Callado Estela 2015. 
Callado Estela, E. 2012a. «Dignidades contra canónigos en la catedra de Valencia durante el siglo XVII». Estudis 38, 117-137.

Callado Estela, E. 2012b. «Barberá, José», en Diccionario crítico de juristas españoles, portugueses y latinoamericanos III: 67. Barcelona: JP.

Callado Estela, E. 2013. «El clero valentino en la revuelta de los labradores de la Huerta de 1663», en Campo y Campesinos en la España Moderna: I, 535-546. León: Universidad de León.

Callado Estela, E. 2014. «El asesinato del chantre don Ventura Ferrer Clérigos y bandos en la seo valentina seiscentista». Hispania Sacra LXVI: 109-131. https://doi.org/10.3989/hs.2013.048

Callado Estela, E. 2015. "Nombramientos reales de canónigos y dignidades de la catedral de Valencia en la segunda mitad del siglo XVIII», en E. Callado Estela (ed.), La Catedral Ilustrada. Iglesia, sociedad y cultura en la Valencia del siglo XVIII 3: 51-100. Valencia: Alfons el Magnànim.

Callado Estela, E. (en prensa). «El arzobispo de Valencia don Martín López de Hontiveros», en E. Callado Estela (ed.), La Catedra Barroca. Iglesia, sociedad y cultura en la Valencia del siglo XVII. Valencia: Alfons el Magnànim.

Canet Aparisi, T. 1986, «Iglesia y poder real en la Valencia del Quinientos: la figura del canciller del Reino». Saitabi XXXVI: 227-234.

Cereceda, F. 1944. «El litigio de los cabildos y su repercusión en las relaciones con Roma (1551-1556)». Razón y fe 130: 215-234.

Ciprés de Povar, S. 1641. Origen y progresso de las pabordrías de la santa metropolitana iglesia de Valencia. Roma: Imprenta de la Cámara Apostólica.

Díaz Rodríguez, J. 2010. "Cabildos catedralicios y clero capitular en el Antiguo Régimen: estado de la cuestión». Revista de historiografía 13: 82-99.

Díaz Rodríguez, A. J. 2012. El clero catedralicio en la España Moderna: los miembros del cabildo de la catedral de Córdoba (1475-1808). Murcia: Universidad de Murcia.

Domínguez Ortiz, A. 1985. Las clases privilegiadas en el Antiguo Régimen. Madrid: Istmo.

Esquerdo, O. 2001. Nobiliario valenciano. Valencia: Biblioteca Valenciana. 2 vols.

Esteban, L. 2010. Obispos nacidos en Teruel y provincia. Valencia: León Esteban.

Felipo Orts, A. y Callado Estela, E. 2016. Entre la cátedra y el púlpito. Los pavordes de la Universidad de Valencia (siglos XVI-XVII). Valencia: Universitat de València.

Fernández Terricabres, I. 2000. Felipe II y el clero secular. La aplicación del concilio de Trento. Madrid: Sociedad Estatal para los Centenarios de Felipe II y Carlos V.
García Martínez, S. 1991. Valencia bajo Carlos II. Valencia: Ayuntamiento de Villena.

García Sánchez, J. 2016. Aportaciones a la cultura asturiana del siglo XVII. Manuscritos inéditos de los años 1665-1667. Dos poemas en asturiano. Oviedo: Real Instituto de Estudios Asturianos.

Goñi Gaztambide, J. 1975. "Los cabildos españoles y la confirmación del concilio de Trento». Annuarium Historiae Conciliorum 7: 425-458.

Guía Marín, LI. J. 1975. "Los estamentos valencianos y el duque de Montalto: los inicios de la reacción foral». Estudis 4: 129-146.

Guitarte Izquierdo, V. 1985. Obispos auxiliares en la historia del arzobispado de Valencia. Castellón: Ayuntamiento de Castellón.

Irigoyen López, A. 2001. Entre el cielo y la tierra, entre la familia y la institución. El cabildo de la catedral de Murcia en el siglo XVII. Murcia: Universidad de Murcia.

Jiménez Sureda, M. 1992. L'Església catalana sota la monarquia dels Borbons. La catedral de Girona en el segle XVIII. Barcelona: Abadía de Montserrat.

Jordán Selva, A. 1677. Sumario de la maravillosa vida y heroicas virtudes del venerable padre doctor Domingo Sarrió, de la Real Congregación del Oratorio de la ciudad de Valencia. Valencia: Francisco Mestre.

Marín López, R. 2007. «Historiografía sobre cabildos eclesiásticos. Estado de la cuestión y perspectivas de investigación», en A. L. Cortés Peña (ed.), La Iglesia española en la Edad Moderna. Balance historiográfico y perspectivas: 80-97. Madrid: Abada.

Marín Martínez, T. 1948. «Primeras repercusiones tridentinas: el litigio de los cabildos españoles. Su proceso en la diócesis de Calahorra». Hispania Sacra 1: 325-349.

Olmos Canalda, E. 1949. Los prelados valentinos. Valencia: Semana Gráfica.

Pérez Puente, L. 2012. «El cabildo y la universidad. Las primeras canonjías de oficio en México (1598-1616)». Historica XXXVI (1): 53-96.

Pérez Villanueva, J. y Escandell Bonet, B. 2000. Historia de la Inquisición en España y América III. Temas y problemas. Madrid: BAC.

Pons Alós, V. y Cárcel Ortí, M.a M. 2013. «Dignidades y canónigos de la catedral de Valencia en el siglo XVIII», en E. Callado Estela (ed.), La Catedral Ilustrada. Iglesia, sociedad y cultura en la Valencia del siglo XVIII: 103-127. Valencia: Alfons el Magnànim.

Vilar, J. B. 1981. Orihuela, una ciudad valenciana en la España Moderna. Murcia: Patronato Ángel Roger.

Ximeno, V. 1747-1749. Escritores del reyno de Valencia. Valencia: Joseph Estevan Dolz. 2 vols. 